\title{
White blood cell count to mean platelet volume ratio as a novel blood cell parameter. Authors' reply
}

We would like to thank Çelik et al. [1] for the reply to our article "White blood cell count to mean platelet volume ratio: A novel and promising prognostic marker for ST-segment elevation myocardial infarction" [2]. Herein, we wish to make some contributions to their valuable comments. As previously stated, there is a strong discussion on the relationship between blood cell parameters and outcomes in patients with coronary artery disease (CAD) [3-5]. These parameters can be useful in predicting the prognosis in patients with acute coronary syndromes (ACS). It is noteworthy, that novel biomarkers measured by clinicians could potentially provide additional information to the decision-making process and treatment strategy [4]. Indeed, there is growing body of research supporting the hypothesis that white blood cell count to mean platelet volume ratio (WMR) could be a new prognostic indicator that contains these three properties [2, 6]. However, long-term follow-up and large-scale prospective further studies are strongly needed to clarify and prove the predictive value of WMR in patients with CAD and ACS.

Conflict of interest: None declared

\section{References}

1. Celik T, Balta S, Ozturk C, Iyisoy A. Whole blood cell parameters help us to predict the prognosis in patients with acute ST segment elevation myocardial infarction: Myth or reality? Cardiol J, 2016; 23: 357-358. doi: 10.5603/CJ.2016.0037.

2. Çiçek G, Açıkgöz SK, Yayla Ç, Kundi H, İleri M. White blood cell count to mean platelet volume ratio: A novel and promising prognostic marker for ST-segment elevation myocardial infarction. Cardiol J, 2016; 23: 225-235. doi: 10.5603/CJ.a2016.0001.

3. Yayla C, Akboga MK, Canpolat U et al. Platelet to lymphocyte ratio can be a predictor of infarct-related artery patency in patients with ST-segment elevation myocardial infarction. Angiology, 2015; 66: 831-836.

4. Morrow DA, de Lemos JA. Benchmarks for the assessment of novel cardiovascular biomarkers. Circulation, 2007; 115: 949-952 .

5. Doehner W. Diagnostic biomarkers in cardiovascular disease:The proteomics approach. Eur Heart J, 2012; 33: 2249-2251.

6. Dehghani MR, Rezaei Y, Taghipour-Sani L. White blood cell count to mean platelet volume ratio as a novel non-invasive marker predicting long-term outcomes in patients with non-ST elevation acute coronary syndrome. Cardiol J, 2015; 22: 437-445. doi: 10.5603/CJ.a2015.0015.

Gokhan Cicek ${ }^{1}$, Cagri Yayla ${ }^{2}$

${ }^{1}$ Ankara Numune Training and Research Hospital, Cardiology Clinic, Ankara, Turkey, tel: +90 5052485345,e-mail:drvaristor@hotmail.com ${ }^{2}$ Türkiye Yüksek Ihtisas Training and Research Hospital, Cardiology Clinic, Ankara, Turkey 